\title{
Integration of Computer Simulation, Design of Experiments and Particle Swarm Optimization to Optimize the Production Line Efficiency
}

\author{
Morteza Khalaji Assadi ${ }^{*}$, Seyed Mojib Zahraee ${ }^{1}$ and Jalal Taghdisi ${ }^{2}$
}

${ }^{1}$ Mechanical Engineering Department, Universiti Teknologi Petronas (UTP), Bandar Seri Iskandar, Malaysia

${ }^{2}$ Department of Management, Islamic Azad University, Mashhad, Razavi Khorasan, Iran

\begin{abstract}
The goal of this paper is to optimize the productivity of manufacturing system by integrating computer simulation, design of experiments (DOE) and particle swarm optimization (PSO) algorithm. Optimizing productivity of colour factory was considered as the case of this study. To evaluate and estimate the effect of main factors, $2^{n}$ factorial design with higher and upper levels and centre points was considered. After obtaining the significant factors, the local optimum setting of the significant factors was determined using the steepest ascent method and response surface methodology (RSM) approach. Finally, the global optimum productivity was achieved by computer programing of PSO method. Base on the final result, maximum productivity occurs in the point of 87.23 that is relevant to number of labour $(B)=26$ and failure time of lifter $(C)=78.04 \mathrm{~min}$. In addition, other two factors $A$ (Service rate of Delpak mixer) and $\mathrm{D}$ (Number of permil) should be located at low level to obtain maximum productivity.
\end{abstract}

Keywords: Design of experiments; Computer simulation; Response surface methodology; Particle swarm optimization

\section{Introduction}

Computer simulations plays a significant role in dealing with the operational problems as well as improving the productivity and efficiency in different fields, such as manufacturing systems [1] port container terminal [2] supply chain management [3] different services such as bank system [2] and construction management [4], which are not easy to model. There would large portions favourable circumstances about utilizing computer simulation in the manufacturing systems through saving the cash investment, increasing the resource utilization, diminishing procedure cycle time, and increasing of the throughput (Sun Furthermore Ming).

Design of experiments (DOE) is a mathematical, statistical, and systematic approach for building a relationship between effective process factors and the output of that process [5]. In other words, it will be used to figure cause-and-effect and interactional between parameters the place done particular case figure at once methodology may be not be allowed. Analysis for DOE will be crucial to deal with transform inputs so as will optimize those procedure yield (Chuang Furthermore Hung). There have been conducted some scientific research studies predicting the behaviour of the system with DOE along with computer simulation. Traditionally, the experimental designs have been applied in physical experiments, such as agriculture experiments and clinical tests. In order to decrease the cost of doing experiments and large number of input parameters, computer simulation is suggested as a powerful and useful tool that helps to do experimental trials in a cost-effective and reliable environment [6]. Manufacturing systems is comprised of complex combination of resources such as material, labor, machines. It would be a difficult task to find the root of problem in timely manner and effectively when a production line is faced with a problem [7]. For solving these difficulties, engineers can use the experimental design to determine the significant factors that have a considerable effect on the efficiency of production line.

Tsai proposed the use of DOE and computer simulation in order to optimize the operation of joined manufacturing systems. This research claimed that this technique could assess the operating conditions in multifaceted systems simultaneously. Additionally [8] used computer simulation in order to model a sawmill factory in Chile. In order to increase the productivity of wood process, bottlenecks and proposing alternatives that would yield to an improvement in system productivity was assessed. In order to meet the essential demands, the minimum number of human and physical resources is founded by using the design of experiments. The final result showed that the productivity will be improved improvement up to $25 \%$ by combining the computer simulation and design of experiments [9]. Consider a semiconductor company to use the design of experiments, simulation and economic analysis in the process of decision making. Integrating the DOE along with the computer simulation play an important role to enhance the performance of the simulation process, diminishing the trial and error to find solutions [10-13] implemented the DOE and computer simulation in order in order to determine the optimum combination of factors that have the significant effect on the process productivity. Another investigation applied statistical analysis and computer simulation to recognize and to weigh the significance of different factors in the production line. Based on the final result, the two factors i.e. B (Number of labor) and C (Failure time of lifter) have the most significant effect on the manufacturing system productivity $[14,15]$ used computer simulation and taguchi method in order to assess the effect of controllable and uncontrollable factors on the total output production in a colour manufacturing industry. Final result showed that the maximum desirability of productivity will be achieved when the value of factors such service rate of delpak machine=UNIF $(30,40)$, number of labour $=14$, inspection time $=120$ and number of Permil $=5$. They claimed that Taguchi Method plays an efficient and suitable role in the process improvement, proposing adjustments that will provide an improvement in the productivity. Previous studies on this field

*Corresponding author: Morteza Khalaji Assadi, Mechanical Engineering Department, Universiti Teknologi PETRONAS (UTP), Bandar Seri Iskandar, Malaysia, Tel: 605368 7202; E-mail: morteza.assadi@petronas.com.my

Received April 25, 2016; Accepted April 27, 2016; Published April 30, 2016

Citation: Assadi MK, Zahraee SM, Taghdisi J (2016) Integration of Computer Simulation, Design of Experiments and Particle Swarm Optimization to Optimize the Production Line Efficiency. Int J Swarm Intel Evol Comput 5: 136. doi: 10.4172/2090-4908.1000136

Copyright: (c) 2016 Assadi MK, et al. This is an open-access article distributed under the terms of the Creative Commons Attribution License, which permits unrestricted use, distribution, and reproduction in any medium, provided the original author and source are credited. 
show that the simulation results can be used as an input to the design of experiment. Simulation and statistical analysis are some tools to analyse the behaviour of a system. The goal of this paper is integrating DOE and computer simulation to determine the main factors that have significant effect on productivity in a manufacturing system. Additionally, this paper focuses on find the local and global optimum solutions by implementing the RSM approach and PSO algorithm. It is claimed that performing this investigation will help the companies, managers and engineers to optimize resource usage in order to increase total output production and optimize the productivity in a timely and cost-effective manner. A colour Factory is chosen as a case study in this research. This factory is a leading producer of industrial and building paint.

\section{Material and Methods}

\section{Response surface methodology (RSM)}

RSM is an optimization approach in order to determine the input combination of variables that maximize or minimize the objective function [16]. The RSM includes a combination of mathematical and statistical techniques that are a powerful approach to modelling and analysing of problems in which a response of interest is influenced by several parameters and the objective is optimize the outcomes [17]

\section{Particle swarm optimization (PSO) algorithm}

PSO is a developmental algorithm that was suggested by James Kennedy and Russell Eberhart in 1995 to determine the best solution of problems [18]. It is comprised of Swarm Intelligence and Collective Intelligence and is a sub-field of Computational Intelligence. Moreover, it is related to other Swarm Intelligence algorithms such as Ant Colony [19]. Because of fast convergence, PSO has gradually been used in identification of graphics, optimization of clustering, scheduling assignment, network optimization and multi-objective optimization [19].

\section{Simulation Model Development}

At the beginning, an initial model of production line is constructed using ARENA 13.9 software. After detailed data is collected and analysed, details of the elements are recognized and added to the simulation model. Following that the simulation model is built, the simulation model is tested so that the model is all rightly concerned whether a model and its result are correct. Model verification and validation are applied to assess the correction of model.

\section{Model validation}

After simulating the production line of this company, it is time to validate it. In order to conduct validation, the number of simulation runs for achieving the desired level of accuracy should be calculated by the below formula:

$$
\text { Number of replications } \left.=\mathrm{t}_{\frac{\alpha}{2}, \mathrm{n}-1} * S(m)\right) /(\varepsilon *(m))
$$

Therefore for calculating the number of simulation runs, five simulation runs are considered.

$$
\begin{aligned}
& \overline{\mathrm{X}}(m)=\text { Mean }=20120 \\
& \mathrm{~S}(\mathrm{~m})=\text { Standard Deviation }=22.36068 \\
& N=\text { number of replication }=\left(\frac{2.132 * 22.36068}{0.05 * 20120}\right)=0.04
\end{aligned}
$$

This result means that the one number of replication is enough to achieve the desired accuracy. Some information including number of product outputs and production working time that were available for 2 working years were added to the company's documents especially sales list. After gathering the information, they were compared to the obtained results of the simulation. Average of total production time for orders are indeed attained by subtracting time of production completion and time of order. Based on results the variation between the actual data and simulation result are less than $7 \%$ that is acceptable.

\section{Choosing the factors and levels}

In order to conduct the DOE and simulation experiment the factors should be selected. As discussed before, the response variable considered in DOE is process productivity. For the choice of experimental design, due to the small number of factors investigated, the full factorial design is used. In the factorial design all possible combination of factors are in an experiment considered. The experiment is also replicated for two times. In addition, each factor has two levels. Therefore, a full factorial experiment includes $2^{\text {n }}$ runs. Having considered two replications for experiments and three additional centre points, 35 runs are included in the design. Table 1 shows the factors which are selected in this thesis are:

\section{PSO procedure}

The PSO algorithm is a set of particles that move around the search space affected by their own best past location and the best past location of the whole swarm or a close neighbour. In each iteration a particle's velocity is updated applying:

$$
V_{i}(t+1)=V_{i}(t)+C_{1} * \operatorname{rand}() *\left(p_{i}^{b} e s t-p_{i}(t)\right)+C_{2} * \operatorname{rand}() *\left(p_{g} \text { best }-p_{i}(t)\right)
$$

Where $V_{i}(t+1)$ is the new velocity for the $\mathrm{i}^{\text {th }}$ particle, $\mathrm{C}_{1}$ and $\mathrm{C}_{2}$ are the weighting coefficients for the personal best and global best positions respectively, $\mathrm{p}_{\mathrm{i}}(t)$ is the $\mathrm{i}^{\text {th }}$ particle's position at time $\mathrm{t}, \mathrm{p}_{\mathrm{i}}^{\text {best }}$ is the $\mathrm{i}^{\text {th }}$ particle's best known position, and $\mathrm{p}_{\text {gbest }}$ is the best position known to the swarm. The rand ( ) function generates a uniformly random variable $\in[0,1]$.

Variants on this update equation consider best positions within a particles local neighbourhood at time t. A particle's position is updated using Brownlee [20].

$$
\mathrm{p}_{\mathrm{i}}(\mathrm{t}+1)=\mathrm{p}_{\mathrm{i}}(\mathrm{t})+\mathrm{v}_{\mathrm{i}}(\mathrm{t})
$$

\section{Result and Discussion}

\section{Perfuming simulation experiment}

After knowing the parameter setting and experimental design, the collection of data should be gathered form the simulation model running. The response of this experiment is the Productivity based on the total output production that is measured by using ARENA software result.

\section{Statistical analysis}

ANOVA is used to perform the percentage of correct classification of the statistical significance of the defects. The P-value $(\mathrm{P})$ in the table

\begin{tabular}{|c|c|c|c|}
\hline Factor & \multicolumn{3}{|c|}{ Level } \\
\hline Service rate of Delpak mixer (A) & -1 & 0 & 1 \\
\hline Number of labor (B) & 14 & 17 & 20 \\
\hline Failure time of lifter (C) & 30 Minutes & 45 Minutes & 60 Minutes \\
\hline Number of permil (D) & 3 & 4 & 5 \\
\hline
\end{tabular}

Table 1: Factors and levels. 
Citation: Assadi MK, Zahraee SM, Taghdisi J (2016) Integration of Computer Simulation, Design of Experiments and Particle Swarm Optimization to Optimize the Production Line Efficiency. Int J Swarm Intel Evol Comput 5: 136. doi: 10.4172/2090-4908.1000136

Page 3 of 4

was used to determine which of the effects in the model are statistically significant. If the p-value is less than or equal to á, so the effect can be concluded is significant. If the p-value is greater than $\alpha$, then we conclude that the effect is not significant [21]. Table 2 shows that the curvature is significant. In addition, that main effect B (Number of labor), C (Failure time of lifter) are significant factors.

\section{Conducting the POSA}

As can be seen in the conducting the POSA curvature is significant, therefore it is concluded that the first order model is not adequate for RSM and a second order regression model is estimated by least square method. The second-order regression model is obtained as follow:

$$
\begin{aligned}
& \hat{Y}=\beta_{0}+\beta_{1} X_{1}+\beta_{2} X_{2}+\beta_{12} X_{1} X_{2}+\beta_{11} X_{11}{ }^{2}+\beta_{22} X_{22}{ }^{2} \\
& \hat{Y}=86.04+4.81 \mathbf{B}-2.04 \mathbf{B C}-1.58 \mathbf{B}^{2}
\end{aligned}
$$

By taking account the second order regression model, the steepest ascent method is used to find the local optimum solution. POSA is an approach to move sequentially in the direction of maximum increase in the response variable. To do this method the step size for variable $\Delta \mathrm{X}_{\mathrm{i}}$ and according to that also $\Delta \mathrm{X}_{\mathrm{j}}$ is chosen then check the responses. In this paper the Minitab macro was used to calculate the path of steepest ascent. For acquiring the best point in this phase the second-order model is applied.

$$
\begin{aligned}
& X_{b}=\frac{E_{1}-17}{3}, B(14,20) \\
& X_{c}=\frac{E_{2}-45}{15}, C(30,60)
\end{aligned}
$$

The highlighted area in the Table 3 shows that the local optimum point is considered as $\mathrm{y}=86.01$ with $\mathrm{B}=23$ and $\mathrm{C}=67.03$

\section{Finding global optimum by PSO algorithm}

The resulted second regression model from RSM is used as the input variable of PSO algorithm. Table 4 shows the result of implementing PSO algorithm in order to find the global optimum value of number of labour (B) and failure time of lifter (C). Based on the final result, the maximum response (Productivity) occurs in the point of 87.23 that is relevant to high level of both significant factors which is equal to

\begin{tabular}{|c|c|c|c|c|c|c|}
\hline Source & DF & Seq SS & Adj SS & Adj MS & F & P \\
\hline Main Effects & 4 & 1113.93 & 1113.93 & 278.48 & 5.89 & 0.003 \\
\hline 2-Way Interactions & 6 & 148.22 & 148.22 & 24.7 & 0.52 & 0.784 \\
\hline 3-Way Interactions & 4 & 144.59 & 144.59 & 36.15 & 0.76 & 0.562 \\
\hline 4-way Interaction & 1 & 73.66 & 73.66 & 73.66 & 1.56 & 0.228 \\
\hline Curvature & 1 & 1577.05 & 1577.05 & 1577.05 & 33.35 & 0 \\
\hline Residual Error & 18 & 851.24 & 851.24 & 47.29 & - & - \\
\hline Pure Error & 18 & 851.24 & 851.24 & 47.29 & - & - \\
\hline Total & 34 & 3908.68 & - & - & - & - \\
\hline
\end{tabular}

Table 2: Analysis of variance (ANOVA) for productivity.

\begin{tabular}{|c|c|c|c|c|c|}
\hline Steps & $\boldsymbol{x}_{\boldsymbol{b}}$ & $\boldsymbol{x}_{\boldsymbol{c}}$ & $\boldsymbol{E}_{\mathbf{1}}$ & $\boldsymbol{E}_{\mathbf{2}}$ & Response \\
\hline Origin & 0 & 0 & 17 & 45 & 82.2 \\
\hline$\Delta=$ Step Size & 1 & 0.734 & & & \\
\hline Origin + $1 \Delta$ & 1 & 0.734 & 20 & 56.01 & 83.5 \\
\hline Origin $+2 \Delta$ & 2 & 1.468 & 23 & 67.03 & 86.1 \\
\hline Origin +3 $\Delta$ & 3 & 2.202 & 26 & 78.04 & 84.5 \\
\hline Origin $+4 \Delta$ & 4 & 2.936 & 29 & 89.06 & 78.1 \\
\hline Origin $+5 \Delta$ & 5 & 3.67 & 32 & 100.07 & 69.2 \\
\hline
\end{tabular}

Table 3: Result of the POSA for the productivity.

\begin{tabular}{|c|c|c|}
\hline Iteration & NFE & Best Productivity \\
\hline 1 & 400 & 34.2449 \\
\hline 2 & 600 & 34.2449 \\
\hline 3 & 800 & 37.4479 \\
\hline 4 & 1000 & 81.0048 \\
\hline 5 & 1200 & 87.23 \\
\hline 6 & 1400 & 87.23 \\
\hline 7 & 1600 & 87.23 \\
\hline 9 & 1800 & 87.23 \\
\hline 10 & 2000 & 87.23 \\
\hline & 2200 & 87.23 \\
\hline
\end{tabular}

Table 4: Result of PSO algorithm.

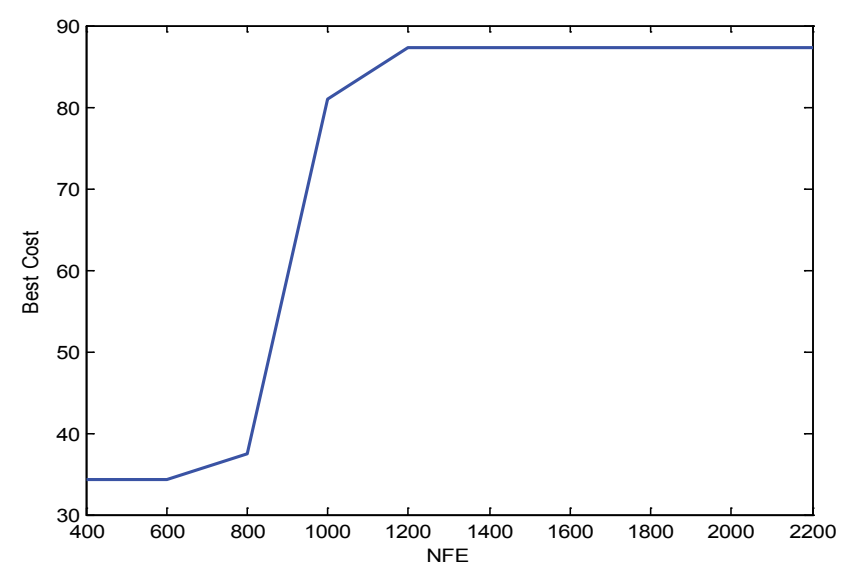

Figure 1: Graphical view of PSO result.

Number of labour $(B)=26$ and Failure time of lifter $(C)=78.04 \mathrm{~min}$ Moreover Figure 1 shows the graphical result of PSO algorithm.

\section{Discussion}

Productivity optimization is one of the most controversial issues in the discrete production systems. In this paper the suggested integrated approach helps the engineers and managers to find the optimum solutions in a cost-effective and timely manner. Since in real world implementing of different scenarios and alternatives in the production line impose extra cost and time to the companies. In this paper, integration of computer simulation, DOE and PSO algorithm cause to find the global optimum of resources in a color factory as a case study. Table 5 shows the productivity value in three conditions which includes the current state, result of POSA method and PSO algorithm. Therefore it is concluded that the best productivity is relevant to the PSO algorithm which is equal to 87.23.

\section{Conclusion}

The goal of this paper was to productivity optimization of

\begin{tabular}{|c|c|c|c|}
\hline Factor & Current state & $\begin{array}{c}\text { POSA } \\
\text { method }\end{array}$ & PSO algorithm \\
\hline Service rate of delpak mixer (A) & UNIF(20,40) & UNIF(20,40) & UNIF(20,40) \\
\hline Number of labor (B) & 20 & 23 & 26 \\
\hline Failure time of lifter (C) & 60 & 67.03 & 78.04 \\
\hline Number of permil (D) & 5 & 3 & 3 \\
\hline Productivity & 78.03 & 86.01 & 87.23 \\
\hline
\end{tabular}

Table 5: Productivity value in current state, local optimum and global optimum. 
Citation: Assadi MK, Zahraee SM, Taghdisi J (2016) Integration of Computer Simulation, Design of Experiments and Particle Swarm Optimization to Optimize the Production Line Efficiency. Int J Swarm Intel Evol Comput 5: 136. doi: 10.4172/2090-4908.1000136

manufacturing system using computer simulation along with Design of Experiment and particle swarm optimization (PSO) algorithm. A case study was conducted in order to achieve this objective. In order to conduct the simulation experiments, model of manufacturing system was created using the Arena software. After conducting the DOE experiment the two factors which are B (Number of labor) and C (Failure time of lifter) were significant [22]. After obtaining the significant factors, the local optimum setting of the significant factors was determined using the steepest ascent method and response surface methodology approach. Finally, the global optimum productivity was achieved by computer programing of PSO method that shows the maximum productivity occurs in the point of 87.23 that is relevant to Number of labor $(B)=26$ and Failure time of lifter $(C)=78.04$ min. In addition other two factors A (Service rate of Delpak mixer) and D (Number of permil) should be located in low level to obtain maximum productivity. The combined computer simulations, design of experiment method and PSO algorithm is new approach and help the engineers and managers to identify the global optimal solutions. Moreover, applying computer simulation and statistical analysis in the manufacturing systems is very useful and cost effective where the weakness of the system will be found after doing the experimentation. Further study can be done by considering the other responses such as cycle time, cost and resource utilization. In addition, there are other methods such as Taguchi method can be applied to determine the optimum setting for the experiment by considering the effect of the controllable and uncontrollable factors (Noise).

\section{References}

1. Basler F, Sepulveda J (2004) The use of simulation and design of experiment for productivity improvement in the sawmill industry. Proceeding of 36 th winter simulation conference pp: 1218-1221.

2. Brownlee J (2011) Clever Algorithms: Nature-Inspired Programming. Recipes $1^{\text {st }}$ edition.

3. Box G, Wilson K (1951). On the experimental attainment of optimum conditions Journal of the Royal Statistical Society 13: 1-38.

4. Chuang SC, Hung YC (2010) Uniform design over general input domains with applications to target region estimation in computer experiments. Computational Statistics \& Data Analysis 54: 219-232.

5. Clerc M (2006) Particle Swarm Optimization. Hermes Science Publishing Ltd London.

6. Ebrahimi Y, Abourrizk S, Fernando M, MohaS (2011) Simulation modeling and sensitivity analysis of a tunnelling construction project's supply chain Engineering. Construction and Architectural Management 18: 462-480.

7. Hatami M, Zahraee SM, Ahmadi M, Golroudbary SR, Rohani JM (2014)
Improving Productivity in a Bank System by Using Computer Simulation. In Applied Mechanics and Materials 606: 259-263.

8. Hatami M, Zahraee SM, Khademi A, Shahpanah A, Rohani JM (2014) Evaluating the Effect of Main Factors in Manufacturing Production Line Based on Simulation Experiment. Applied Mechanics and Materials 606: 199-203.

9. Kennedy J, Eberhart RC (1995) Particle swarm optimization. Proceedings IEEE international conference on neural networks 4: 1942-1948.

10. Kleijnen J (2008) Response surface methodology for constrained simulation optimization: an overview simulation model practice 16: 50-64.

11. Memari A, Zahraee SM, Anjomanshoae A, Rahim A (2013) Performance Assessment in a Production-Distribution Network Using Simulation. Caspian Journal of Applied Sciences Research 2: 48-56.

12. Montgomery D (2009) Basic Experiment Design for Process Improvement Statistical Quality Control USA: John Wiley and Sons.

13. Montevechi J, Pinho A, Leal F, Marins F (2007) Application of design of experiment on the simulation of a process in an automotive industry. Proceedings of the Winter Simulation Conference pp: 1601-1609.

14. Nazzala D, Mollaghasemi M, Anderson D (2006) A simulated-based evaluation of the cost of cycle time reduction in Agree Systems wafer fabrication facility- a case study. International Journal of Production Econimics pp: 300-313.

15. Sadeghifam AN, Zahraee SM, Meynagh MM, Kiani I (2015) Combined use of design of experiment and dynamic building simulation in assessment of energy efficiency in tropical residential buildings. Energy and Buildings 86: 525-533.

16. Shahpanah A, Poursafary S, Shariatmadari S, Gholamkhasi A, Zahraee SM (2014) Optimization Waiting Time at Berthing Area of Port Container Terminal with Hybrid Genetic Algorithm (GA) and Artificial Neural Network (ANN). In Advanced Materials Research 902: 431-436.

17. Shahpanah A, Hashemi A, Nouredin G, Zahraee SM, Helmi SA (2014) Reduction of Ship Waiting Time at Port Container Terminal Through Enhancement of the Tug/Pilot Machine Operation. Jurnal Teknologi p: 68.

18. Tsai CS (2002) Evaluation and optimisation of integrated manufacturing system operations using Taguch's experiment design in computer simulation. Computers \& Industrial Engineering 43: 591-604.

19. Zahraee SM, Golroudbary SR, Hashemi A, Afshar J, Haghighi M (2014) Simulation of Manufacturing Production Line Based on Arena. In Advanced Materials Research 933: 744-748.

20. Zahraee SM, Rezaei G, Shahpanah A, Chegeni A, Rohani JM (2014) Performance Improvement of Concrete Pouring Process Based Resource Utilization Using Taguchi Method and Computer Simulation. Jurnal Teknologi 69: $17-24$

21. Zahraee SM, Shariatmadari S, Ahmadi HB, Hakimi S, Shahpanah A (2014) Application of Design of Experiment and Computer Simulation to Improve the Colour Industry Productivity: Case Study. Jurnal Teknologi 68: 7-11.

22. Zahraee SM, Chegeni A, Rohani JM (2015) Characterization of Manufacturing System Computer Simulation using Taguchi Method. Jurnal Teknologi p: 72. 